\title{
Effects of Gender-Based Violence Towards Young Females: The Case of Vhufuli Village in Thohoyandou, Limpopo Province-South Africa
}

\author{
Tsoaledi Thobejane*
}

Institute for Gender and Youth Studies, University of Venda, P/Bag X 5050, Thohoyandou-0950, South Africa

\begin{abstract}
Gender based violence towards young women is a pandemic experienced mostly by women of all classes and age in different settings, spheres of life and environment. It affects the victim both socially, emotionally, psychologically and physically. Gender based violence is caused by various factors such as substance abuse, lack of education as well as gender norms, socialization and aggressive behavior of men. This study explored the experiences of young women regarding gender-based violence and factors that contribute to this scourge. The research was qualitative in nature and used non-probability sampling as well as snowball and purposive sampling to gather the data. The population was young women between the ages of 12-25 from Vhufuli village. Data was collected using semi-structured interviews. The key finding of the study is that young women are experiencing sexual abuse, physical abuse, emotional abuse, economic and psychological abuse at the hands of their partners and parents. The recommendations are that policy makers need to regulate laws that will also be enforced, as a way of fighting against gender-based violence. There is a need to educate our communities about the dangers posed by patriarchy, and to also understand how hegemonic masculinities can be toxic in our communities. Social workers could also help by coming up with early intervention strategies that may assist in curbing the pandemic of domestic violence.
\end{abstract}

Keywords: Intimate partner violence, Gender-based violence, Physical abuse, Emotional abuse, Psychological abuse.

\section{INTRODUCTION}

Gender based violence is violence that occurs between men and women and is based on the unequal power relations between men and women, in which the women are usually the victim. Gender based violence is violence that is specifically directed to an individual based on one's sexual orientation. It includes physical, sexual, economic and psychological harm (Benoit, Shumka, Phillips, Kennedy \& Belle-Isle, 2015).

While gender-based violence occurs to women in all areas of life, the family setting is the place where young females/women experience the most violence. According to World Health Organization (2013) estimates, nearly one-third $(30 \%)$ of all women worldwide who have ever lived in a relationship and stayed with their parents and father/male figure have experienced physical/ sexual violence.

Domestic violence which is also referred to as intimate partner violence (IPV) involves the following: Spousal violence, battering, forced marriage, honour crimes, dowry related violence, sexual abuse, sexual harassment, marital rape, intimidation, stalking, threats to hurt the person or their loved ones, humiliation, female genital cutting, other traditional practices

*Address correspondence to this author at the Institute for Gender and Youth Studies, University of Venda, P/Bag X 5050, Thohoyandou-0950, South Africa; E-mail: tsoaledi.thobejane@univen.ac.za harmful to women and girls, violence related to exploitation, trafficking, sexual slavery, forced prostitution, economic abuse, forced pregnancy, forced sterilization, forced abortion, abuse in pregnancy, coercive use of contraception, female infanticide, and pre-natal sex selection (WHO, 2013).

The primary targets of GBV are women and adolescent girls, but not only are they at high risk of GBV, they also suffer exacerbated consequences as compared with what men endure. Because of gender discrimination and their lower socio-economic status, women have fewer options and less resources at their disposal to avoid or escape abusive situations and to seek justice (Rafferty, 2013). They also suffer consequences on their sexual and reproductive health, including forced and unwanted pregnancies, unsafe abortions and deaths, traumatic events, and higher risks of sexually transmitted infections (STIs) and HIV (UNFPA Strategy and Framework for Action to Addressing GBV, 2008-2011).

Gender based violence towards young women or females is a universal phenomenon that persists in all countries of the world, and the perpetrators are often well known to the victims (Semahegn \& Mengistie, 2015). Violence Against Women (VAW) in family settings is also a global issue. It deprives women of their right and liberty. In most countries, the male has been historically and traditionally considered the provider and powerful figure, and that is the basis for 
the exercise of control over females. Globally, it is estimated that, one in every three young women is beaten, raped and otherwise abused in their lifetime. However almost every society of the world condones it (Peterman, Palermo \& Bredenkamp, (2012).

Young women/females are affected by killings committed by intimate partners and other family members as confirmed by the latest UNODC global homicide study. While women do represent about $20 \%$ of homicide victims worldwide, they make up almost two-thirds of all persons killed by an intimate partner and other family members (UNODC, 2014).

According to Lakshmi (2011), in the United States, one-third of women are murdered each year, and are killed by their intimate partners, whereas $83 \%$ of girls aged 12 to 16 experienced some form of sexual harassment in public school which can be argued that it is a learned behavior from boys. In India, 22 young women are killed each day in dowry-related murders. In Sao Paolo, Brazil, a woman is assaulted every 15 seconds. Between 40 and 50 percent of women advancements in the European Union countries experience unwanted sexual advancements, physical contact or other forms of sexual harassment at their workplace, however it is worse within family settings where there is supposed to be privacy.

The South East Asian Region has one of the highest incidences of Gender based Violence in the world. This is a result of overall inferior status of women and girls and of unequal power relations between genders. The report notes that more than 5,000 women are killed every year in India because their in-laws consider their dowry inadequate (Sharma, 2015). Studies on South Asia also suggest that a significant proportion of young women are physically abused during pregnancy (UNICEF, 2014). In Nepal, violence during pregnancy accounts for an estimated $15 \%$ of all GBV cases within family contexts in which at first their parents mistreat them and on later stages state their fathers sexually assault them, threaten to chase them away. The Nepal Ministry of Health's 2001 Demographic Survey found that on average, more than $40 \%$ of men thought that one of the following was a justification for beating their daughters and women: burning food, answering back when they are talking to them, going out without telling the man, neglecting the children, and refusing to have sex (Eng, Szmodis \& Grace, 2017).

The practices of early and forced marriages is a form of child exploitation and sexual violence because young females are forced into marriage and a sexual relationship and putting their health at risk, limiting their ability to obtain an education. In many parts of the world especially in Africa and South Asia, families choose early marriages of their young females because it provides financial stability and safety for themselves and siblings, especially in situation when they are facing financial crisis and where young women can be kidnapped (Parsons, Edmeades, Kes, Petroni, Sexton \& Wodon, 2015). In North America, early marriages of girls are associated with polygamy and following important religions practices and beliefs (Maluleke, 2012).

In Afghanistan, it is estimated that $57 \%$ of young women are married prior turning 16 , because of the practices of "bride money", such practices create a bad, unconducive situation of early marriages. Family poverty and debts are also factors that lead to young women being considered as assets in exchange for money or any other goods by their families.

Over 5, 000 women die every year around the world because of honour based violence, (WHO, 2012). In Canada approximately 12 honour based violence have been committed over the past 10years, and women and young women were the victims. In Pakistan, turkey, Jordan, Syria, Egypt, Lebanon, Iran, Yemen, morocco, honour based violence has also been reported. We have seen similar rising statistics in Germany, France, and United Kingdom within immigrant communities (Jeffreys, 2014).

The rates of gender-based violence within the family are highest in developing countries, with some of the most extreme rates in the African countries. In SubSaharan Africa, 14.1 million girls are child brides, married before the age of 18 (Lakshmi, 2011). In the Eastern Democratic Republic of Congo 200,000 cases of sexual violence, mostly involving women and young girls have been documented since 1996. In a 2007 survey across eight countries namely Botswana, Lesotho, Malawi, Mozambique, Namibia, Swaziland, Zambia and Zimbabwe, it was revealed that $18 \%$ of women aged 16-60 years had experienced intimate partner violence in the past 12 months. One in every five young females aged 12-17 years said they had been forced or coerced to have sex, and one in 10 said they had forced sex on someone else (Lakshim, 2011).

Gender based violence is a significant problem in South Africa, particularly violence against women and young females (Karim \& Baxter, 2016). South Africa is 
rated amongst the highest country with regard to violence against women. A wide range of socioeconomic factors drive the high levels of gender-based violence. This includes gender inequality, substance abuse and cultural factors (Wechsberg, Myers, Reed, Carney, Emanuel \& Browne, 2013). Limpopo is one of the provinces in South Africa where gender-based violence is rife. Almost $77 \%$ of women in Limpopo have experienced some form of violence both emotionally, economically, physically or sexually (Machisa \& Musariri, 2013).

According to the South African Police Service, more than 55,097 rapes were reported in $2009 / 10$. However, research done in 2009 revealed that only 1 in 25 rapes are reported annually. Half of all female homicides in South Africa are committed by an intimate partner, and the rate of female homicide by an intimate partner is six times the global average, those are types of genderbased violence that are leading in South Africa especially within family context. According to Jewkes and Nduna (2010), $77 \%$ of women in Limpopo, $51 \%$ in Gauteng, $45 \%$ of women in the Western Cape and $36 \%$ of women in $\mathrm{KZN}$ have experienced effects of GBV emotionally, economically, physically or sexually in their lifetime both within and outside intimate relationships, however it is worse in family settings.

Young women within family settings that have abusive and controlling parents and sibling are prone and at increased risk of contracting HIVIAIDS and other sexually transmitted illnesses diseases due to an inability to have control over themselves or condom use when they are forced (Bue, 2014). A survey conducted among 1366 South African women showed that women who were beaten by their partners were $48 \%$ more likely to be infected with HIV than those who were not, and those women living in abusive relationships were often unable to seek voluntary testing and counselling services as they risk long term ill health if they are unable to disclose their HIV status to their abusive partner or seek or comply with medical treatment (Wechsberg et al., 2013).

\subsection{Problem Statement}

Gender based violence towards young women is increasingly becoming an endemic globally and the worst part is that it happens to all classes, cultures, races, religion, educated and uneducated people. Gender based violence towards young women is a very serious problem particularly in South Africa. In this country, women continue to be submissive, marginalized and subjected to maltreatment. "Culture" and "head of family" tags carry more than enough authority to suppress and deprive women their freedom, and to search for meaning of their lives as well as to make their own decisions about their lives.

Gender based violence is a violation of human rights, yet societies, communities and local people either experience it at first hand, witness it within their families, neighborhoods and feel there's nothing much they can do about it. In Vhufuli village located in Thohoyandou, Limpopo Province of South Africa, women are being abused but are afraid of exposing their loved ones, parents, siblings and partners to the law enforcement agencies because of fear of reprisals.

\subsection{Aim of the Study}

The purpose or aim of the study was to investigate and explore the effects of gender-based violence towards young female women within family settings.

\subsection{Objectives of the Study}

The following are the objectives of the study:

- To explore the effects of gender-based violence towards young females within family contexts.

- To investigate factors that lead to gender-based violence towards women.

- To provide and assist with measures to curb gender-based violence towards young women within family contexts.

\subsection{Research Questions}

- What are the effects of gender-based violence?

- What causes gender-based violence towards young women in family context?

- What can be done to prevent gender-based violence towards young women in family context?

\subsection{Significance of the Study}

This study will serve as an invitation to all people within those families that have victims of gender-based violence to join hands and collectively campaign against this scourge. Organizations that render services to abused women will also be enriched by the outcomes of this study. Hopefully, governments may be 
encouraged by the study to write more policies that may serve as a protective layer to those women who are at the receiving end of gender-based violence.

\subsection{Delimitation of the Study}

The study only placed its focus on women and effects of gender-based violence on them, therefore women from the age of 15-35years were interviewed.

\section{LITERATURE REVIEW}

Gender based violence towards women remains an international scourge and seems to be getting stronger and unabated. Women are said to be weak and ought to be submissive to men. Currently, it is believed that to have impact and influence one needs power to control. The same happens within family settings, wherein conflicts arise from individuals who want to maintain power and control in relationships. The more powerful members of families often use threats, force and violence to obtain compliance from powerless family members (Visser \& Ferrer, 2015).

The relationship between wealth and violence within family contexts causes gender-based violence towards women. It proposes that "men with high income and social standing have access to a wide variety of resources with which to control their wives (Visser et al., 2015). Women's lack of resources also makes them susceptible because what they do, wish to do, plan to do and their reasoning capacity is restricted. Violence towards women in the family also happens to those women who may also have social standing and high income within family contexts (Namy, Carlson, O'Hara, Nakuti, Bukuluki, Lwanyaaga \& Michau, 2017). Lobaka (2017) also indicated that men with limited or no limited wealth and resources may resort to physical force or violence more quickly. Men hate to feel inferior to their women and to send a strong message on who oversees the family, they become extremely abusive and violent. Violence, battery, sexual abuse, forced sex and coercion become the measure they take to force the authority and to deliberately remind family members who is the head of the family (Visser et al., 2015).

\subsection{What Really Exacerbates Violence Against Women? And is this Pandemic Persisting?}

At the core of this pandemic is what feminists call hegemonic masculinities and/or toxic masculinities. These are definitions of men who believe that they were born superior to women. This mythical power is also linked to the political process of knowledge production. Unequal power relationships in societies where those individuals who are at the margins of socio-economic development, are a recipe for violent acts and gender discrimination. South Africa cannot be immune from such societies as it has shown to be highly patriarchal and chauvinistic. Women who are at the receiving end are also victimized by the dominant cultural norms which are part of the "submissive masculinities" that should be defended and advocated for. A feminist scholar by the name of Connell who coined the term "Hegemonic masculinities" inferred that all men receive a patriarchal dividend even if they are excluded from the dominant definitions of masculinity (Hegarty, 2017). It is this dividend that makes them feel they are superior to women. Traditional masculine tendencies include drinking to excess, swearing at women and calling them the "B" word, breaking the rules to appear tougher, being the breadwinner, and believing that men do not have emotions and that they are not supposed to cry, or they should also always be tougher, mean, bullies and in control as well as confident, independent, violent, and aggressive. Men should always, according to patriarchs, punch their women to prove that they are right and in control. Toxic machismo is harmful to men as well as to women because it does not allow men to show their emotions or their 'feminine' side.

\subsection{Theoretical Framework of the Study}

This study relied on radical feminism as a guiding theory to understanding the root causes of genderbased violence in any society. Radical feminism sees domestic violence as having emanated from the sexual relations of power (Thobejane, 2013). The system of patriarchy excludes women from political and economic power, and destroys the potential that women have as a group. This system manifests itself within the family where a man feels that beating his woman is his inalienable right because by so doing, he is viewed as a disciplinarian. Furthermore, feminists have argued that the experiences of women are interlinked with ideological and economic assumptions about women at an international level. Hill-Collins (2013) further argues that the emergence of property and the capitalist mode of production is at the forefront of women's oppression and subjugation.

With the development of capitalism, women are largely pushed to the margins and only relegated to reproductive labour at home. This separation of labour is important to the development of capitalism and 
patriarchy. Capital accumulation cannot be achieved unless patriarchal gender relations are maintained (Thobejane, 2014). Control over women is entrenched in economic, ideological, cultural and political structures. Anything that challenges this set-up is harshly resisted especially by men. Capitalism has channeled African women into commodity production rather than wage labourers. This largely impacts on what men and women think about themselves. This devaluation has led to men to think that women cannot challenge them.

Feminist organizations are striving to deconstruct the male-hegemonic world outlook which presently determines the consciousness and meaningfulness of societies. Feminism is more concerned with critical social science and the politics of empowerment. Feminist thought defines empowerment as a general analysis of the causal factors of powerlessness and collective actions to change the material conditions that women find themselves in.

\section{RESEARCH DESIGN}

The purpose of the study was to have an in-depth understanding of the effects of gender-based violence towards women within family contexts. The study took place in Vhufuli village situated in Limpopo Province, South Africa. The research focused on the physical, social, emotional, and psychological effects of genderbased violence amongst women.

\subsection{Research Approach}

The study embarked on a qualitative approach to get an in-depth understanding of how the effects of gender-based violence towards women within family contexts hinder, exploits and damage women within family settings especially in Vhufuli village situated in the Vhembe district of Limpopo, South Africa. According to Bryman (2016) qualitative research deals with subjective data that is produced by minds of respondents or interviewees.

\subsection{Research Design}

To achieve the aims and purpose of the study, this research used phenomenology as the strategy for investigation. Creswell (2017) views a phenomenological study as a study that describes the meaning of the lived experiences of phenomena or concept for several individuals. Furthermore, Creswell et al. (2017) indicate that it aims to describe what the life world consists of or more specifically what concepts and structures of experience give form and meaning. Davis (2012) state that the root of phenomenology is to understand the phenomena under study and to provide a description of human experience as it is experienced by a subject. The rationale for using phenomenology was that it enabled the researchers to understand the effects of gender-based violence towards women

\subsection{Population}

A population is the aggregation of elements from which the sample is selected (Babbie and Mouton 2010). Welman et al. (2005) define it as the study object and consists of individuals, groups, organizations, human products and events on the conditions to which they are exposed. The population of the study was women who experienced violence in the family domain. The population was easily accessible for the researchers as they reside in the same village.

\section{PRESENTATION OF FINDINGS}

The age brackets of the interviewed participants were between $12-25$ years.

\subsection{Demographic Information of the Participants}

As seen or indicated in the above age characteristics, $25 \%$ of the respondents who fell under the ages of $12-15$ are young women who are still under the guidance of their parents, another $25 \%$ that fell under the ages of 16-19, who have been in intimate partner violence at their youth age brackets, are still under the guidance of their parents. Lastly $50 \%$ fell under the age of 20-25 and have little experience of running their own families and they are young mothers.

Table 1: Age Characteristics.

\begin{tabular}{|c|c|c|}
\hline Age & Number of participants & Percentage $\%$ \\
\hline \hline $12-15$ & 2 & $25 \%$ \\
\hline $16-19$ & 2 & $25 \%$ \\
\hline $20-25$ & 4 & $50 \%$ \\
\hline Total & 8 & $100 \%$ \\
\hline
\end{tabular}

\subsection{Themes}

The table above indicates a pattern of abuse, with relation to the form of abuse, type of abuse the participants endure and experience. Majority of respondents are being battered, raped and sexually 
Table 2: Responses on Individual Types of Violence Experienced

\begin{tabular}{|c|c|c|c|c|}
\hline Response & $\begin{array}{l}\text { Type of violence } \\
\text { experienced }\end{array}$ & $\begin{array}{l}\text { How often they are } \\
\text { abused }\end{array}$ & $\begin{array}{l}\text { At/In which place does } \\
\text { it occur? }\end{array}$ & $\begin{array}{l}\text { Why open /or discrete } \\
\text { about it? }\end{array}$ \\
\hline Respondent A & Forced sex & 4 Times a month & At home & Fear to lose him \\
\hline Respondent B & Raped by the father & 1 time in 3 months & At home, in my bedroom & $\begin{array}{l}\text { He said if I open up about } \\
\text { it, he will kill me }\end{array}$ \\
\hline Respondent C & Battering & Almost every week & $\begin{array}{l}\text { In our bedroom and in } \\
\text { our car on our way back } \\
\text { home }\end{array}$ & $\begin{array}{l}\text { I love him and cannot live } \\
\text { without him }\end{array}$ \\
\hline Respondent D & $\begin{array}{l}\text { Forced to have } \\
\text { unprotected sex }\end{array}$ & $\begin{array}{l}\text { twice a month. Especially } \\
\text { under the influence of } \\
\text { alcohol }\end{array}$ & At home, in my bedroom & $\begin{array}{c}\text { He said I don't trust him, } \\
\text { and it is my responsibility to } \\
\text { have sex with him the way } \\
\text { he wants }\end{array}$ \\
\hline Respondent $\mathrm{E}$ & $\begin{array}{l}\text { Not allowed to look for a } \\
\text { job }\end{array}$ & Every month & At home & $\begin{array}{l}\text { When he is angry he is not } \\
\text { reasonable, and he said it } \\
\text { is a family matter and it } \\
\text { must remain private or else } \\
\text { I will face consequences }\end{array}$ \\
\hline Respondent $\mathrm{F}$ & $\begin{array}{l}\text { Forced to be a house- } \\
\text { wife with no income }\end{array}$ & He told me every month & $\begin{array}{l}\text { At home, while I am at } \\
\text { my mother's place }\end{array}$ & His anger scares me. \\
\hline Respondent G & $\begin{array}{c}\text { Raped, sexually } \\
\text { assaulted and battered }\end{array}$ & Once or twice in 2 months & $\begin{array}{l}\text { He raped me at my } \\
\text { parents' house, } \\
\text { assaulted me at our } \\
\text { house and battered me } \\
\text { at our house too }\end{array}$ & $\begin{array}{l}\text { I feel if I open about it I will } \\
\text { be disappointing my } \\
\text { parents as we believe in } \\
\text { tradition ways }\end{array}$ \\
\hline Respondent $\mathrm{H}$ & Denied visiting relatives & $\begin{array}{l}\text { I have not visited them } \\
\text { for a year. }\end{array}$ & At our home & $\begin{array}{l}\text { I depend on him so } \\
\text { whatever orders he comes } \\
\text { up with,I must obey. }\end{array}$ \\
\hline
\end{tabular}

abused and they accommodate the abuse because they are in fear of putting their lives in danger. This shows that they do wish to open up about their experiences, but their abusive partners and parents are more violent and for that reason they rather keep quiet and allow them to do whatever they want if they are to survive.

Regarding how often they are abused, the table indicates that their partners are at comfort zones. Those who are witnessing the abuse (like children) are being tormented, traumatized daily and are also learning such behaviors because its frequency has become a norm, a way of life and a doctrine.

\subsection{Theme One}

\subsubsection{Physical Effects of Violence}

The questions that were asked to the respondents were as follows: Have you ever experienced abuse or torture from your partner? Have you ever bled in the process of the beatings? Do you have any recent bruise, and do you have past scars? Have you ever been beaten and feel shy to walk around your home and community?
Responses provided by participants were that pain, injuries, bruises and scars have hindered their wellbeing. Another respondent said that while she was looking for a job as a nanny, she was told that she looked untrustworthy and a thief because of the scars on her face. She was told she looked like a dangerous person who will put the employee's child at risk if she would secure a job as a nanny.

The other said she was absent from work for two weeks because she couldn't face her colleagues with a bruise on her cheeks and she was in serious pain. Most information presented was that respondents were used to torture and harassment.

The respondents are also of the same view that all these physical effects are caused by gender-based violence.

Below are the Responses of Physical Effects of Gender-Based Violence

\section{Respondent}

I missed school for almost 2-3 weeks after being beaten by my father. I remember not writing a test because I was badly injured, and I was given a verbal warning by my principal who did not seem to care 
about my ordeal. During my ordeal, I bled profusely to an extend that I thought I was going to die.

\section{Another Respondent}

There was a time when I and my neighbor would go out to search for jobs. On our return, I would be beaten like a child for coming late. Because of the bruises, I would end up not going out anymore for fear that my friends would notice what was going on in my life.

\section{$\underline{\text { Respondent }}$}

Whenever my partner beats me, I remain indoors for a day or two until I get better and on top of that I will be shy to face my younger daughter and to go outside for fear that my neighbors heard my scream and are ready to ridicule me.

\subsection{Emotional Effects}

Young women experience emotional abuse from their parents on a daily basis. They encounter hate speech, are being shouted at, called names, abused and sworn at more frequently.

\section{This is what a Respondent Said in this Regard}

I feel ashamed when friends from school visit me at my home because my father would call me names in their presence, and say I am disgusting and bad influence on my friends.

\section{Another Respondent}

My father calls me a whore. Whenever I think about this I just cry because he often forces himself on me and rapes me. It is like it is me who seduced him, and therefore I should bear the consequences.

\section{Another Respondent}

The father of my child always tells me I am useless and that I deserve to be a prostitute. This really breaks my heart when I think about it because he is the only one I have been seeing, and that I am not the type of girl that sleeps around.

\section{ECONOMIC EFFECTS}

Below are the responses from participants that concur with how economic abuse manifests itself:

I remember asking my parents some lunch money to eat at school. My father said there is no need for money to buy junk food at school because there is a feeding scheme that is operating in the yard of the school. I should therefore go and queue for my own plate of food instead of asking for money.
There was a time that I wanted to buy a study guide which I thought would be helpful to my studies at school, but I was told it is not important because you are given text books at school.

It was around the first semester and we had lots of assignments that needed to be printed out, but I was told I must wait till month end.

I once asked the father of my kids some money to buy milk for the child as it was on sale at a local store. He gave me the money and insisted that I should bring him the receipts.

\subsection{Effects of Sexual Abuse Effects}

Sexual abuse is any act or activity upon another person by force that has to do with issues of sexual intercourse, sexism, and sexual harassment. Young women are abused by their fathers, older brothers and they are afraid to open up about it as they believe they will in turn lose their benefits ((Benoit, Shumka, Phillips, Kennedy \& Belle-Isle, 2015). In this regard, participants said the following:

When at home there's no one except my father and me, he just starts staring at me, and tell me how beautiful I am, and that I am sexy and that I have nice curves, breasts and he wants to sleep with me. I do not have the choice to refuse his demands.

Whenever my partner is drunk he comes home late, he wakes me up almost every time and tells me to put the child away from bed because he wants to have sex with me. In most instances I refuse but he turns out violent. This usually makes me succumb to his demands because of fear that he may kill me in the process of the abuse. I don't want my child to grow up without a mother. So, I end up giving him what he wants.

My partner never agrees to safe sex. He says that it means I don't trust him, or I am the one who is hiding something from him.

My older brother once raped me and told me that if I tell anyone about it he will deny me help and will also do worse things to me. He is aggressive, powerful and also drinks a lot.

\subsection{Social Effects}

Gender based violence goes beyond family contexts. Some perpetrators may have been influenced 
by their upbringing or socio-economic factors (Lakshmi, 2011). In this regard, participants said the following:

I find it very hard to trust other people in my community because if I no longer feel safe at home living with people I know and love; what about the community that does not know anything about me or that cares so little about me? This is very stressful because I am afraid of going out to meet my colleagues, thus making me feeling very isolated and lonely.

Friends I grew up with no longer have time for me. They say I have become weird, emotional and I easily get angry over little things and it is better if they stayed away from me. I no longer have friends and I really need a shoulder to cry on!

I don't feel safe at all walking around in my township, especially when ameeting a man in the streets. I feel shaky, and sometimes it is like there are butterflies in my tummy.

\subsection{Psychological Effects of Domestic Violence and Abuse}

Psychological effects are not tangible, and they are difficult to identify by an ordinary person. The victim and those who studied human behaviour understand this better. Young women are experiencing psychological trauma, and this affects them directly and those close to them indirectly (Karakurt \& Silver, 2013). Below are the responses of the participants in relation to trauma:

Honestly speaking, I don't even have a reason to live, I mean my life is miserable, I find no joy in it, so what is the use to go on living?

I hardly sleep at night, I keep dreaming about all sorts of horrific and scary things, a complete horror and a nightmare!

Sometimes I feel like there's something inside my head; such as many voices speaking at the same time. This confuses me. Sometimes I hear women shouting, screaming, and some voices saying "runaway to save your life!

I am always moody. I feel like I have a heavy load on my mind and that makes me easily lose interest in the outside world. I am not myself anymore, I can feel there are some strange forces controlling me.

I know I am still young, but I don't think I will ever find myself in a romantic relationship. I am forever heartbroken, and I cannot have the courage to enter into a new relationship. I am failing to maintain a simple friendship at the moment. I shudder to think what I will do when the right guy approaches me.

The anger inside me and hatred within my heart is way too much, especially towards adult men. Any man that I met is a constant reminder of the abuse that my father levels against me on a daily basis.

\section{THEME THREE}

\subsection{Causes of Gender-Based Violence}

According to Semahegn \& Mengistie (2015), men consume alcohol for different reasons. But men who are perpetrators of gender-based violence often use alcohol as an excuse to further violate and perpetuate GBV on their partners. Below are the responses of participants whose abusers are known alcoholics.

My father hit me with a plate on my face. That night he was drunk and there was no reason for him to hit me. I bled profusely and vowed that I was going to open a case against him at the nearest police station. But then the following day he denied that he hit me, and said maybe it was a ghost, or that I was possessed by evil spirits that made me to bang my head against the walls of the house! He said that one thing he was certain of is that it was not him!

Another participant said the following:

I had an argument with my boyfriend. He could not stomach the fact that I exchanged words with him. So he left the house and went out to drink. He came back in the middle of the night so drunk that he could not speak. He started yelling at me and telling me how useless I was, and then slapped me so hard on my face!

Another Participant Repeated the Same Sentiments by Saying

When the father of my child is sober, you would swear he is an angel. But wait until he gets drunk. He turns out to be a monster and shouts at everyone in the house. When he is sober he never forces me to have sex with him. He understands that I am not in the mood for it. But when he is drunk he uses extreme force and even goes to an extend of tearing my clothes off.

\section{DISCUSSION OF FINDINGS}

The key findings of the study are in line with literature regarding what most of the respondents have 
experienced. The majority of respondents were subjected to psychological, physical and sexual abuse by known perpetrators within families and their boyfriends. Research established that the types of violence varied considerably among participants, ranging from slapping, punching and kicking and some women being forced to have sex which is often accompanied by physical violence and other types of abuse such as emotional and financial abuse. Outcomes from the study mainly indicate head injuries, back pains, loss of hearing, loss of eyesight and body changes that are experienced by participants because of beatings. The literature also indicates that Violence, battery, sexual abuse, forced sex and coercion are barometers with which men measure their influence in the family and to show who is the boss (Visser et al., 2015). The theoretical base of this behavior is well articulated in Radical feminist standpoint theory when it postulates that the behavior of men is not removed from the system of capitalism in which women are largely pushed to the margins and only relegated to reproductive labour at home. This separation of labour is important to the development of capitalism and patriarchy. Capital accumulation cannot be achieved unless patriarchal gender relations are maintained (Thobejane, 2014). Control over women is also entrenched in economic, ideological, cultural and political structures where men are the most benefactors. Hence their rush to act violently to those who try to undermine their authority.

\subsection{Social Effects}

Young women who experienced abuse suffer selfisolation. They fear to commit to future relationships and they also find it hard to freely interact with others. GBV does not only affect relationship with a spouse but also strains relationships with friends and family members. Young women who are victims of GBV, as one of the participants indicated, are treated differently by those who have noticed some changes in their behavior. This makes them worried to an extend that they become hermits as they feel unloved, unaccepted, unwelcomed and not appreciated. This is further supported by Karakurt and Silver who indicate that mostly young women are experiencing psycho-social trauma, and this affects them directly and those close to them indirectly as they continue become more isolated and unable to function well in their communities (Karakurt \& Silver, 2013).

\subsection{Psychological Effects}

The psychological effects on these young women are experiences of depression, having concurrent suicidal thoughts, self-loath and lack of self-esteem. The study findings indicate that GBV negatively affects the psyche of the victim. As inferred to earlier, GBV can be caused by, inter-alia, some "Hegemonic masculinities" which reinforces a patriarchal dividend on men (Hegarty, 2017).

\section{RECOMMENDATIONS}

This study therefore recommends that policy makers should regulate laws against gender-based violence. These laws should always be enforced as a way of fighting against the scourge. There is a need to educate our communities about the dangers posed by patriarchy, and how hegemonic masculinities can also be toxic in our society. Social workers could also help by coming up with early intervention strategies that may assist in curbing the pandemic of domestic violence and to help victims to heal. Community outreach programmes intended to educate our people against this pandemic should be prioritized.

\section{CONCLUSION}

In the fight against gender-based violence, there must be a concerted effort to educate, empower, and intervene in cases where this scourge seems to be the norm. Thus far,our society has failed a lot of women who died at the hands of their abusive partners, and this trend is continuing unabated. The society must give support and encourage young women who are victims of GBV to stand up and act against it by reporting the abusers irrespective of how close, or how much they love them, to the authorities.

\section{REFERENCES}

Babbie. \& Mouton, J. (2010). The practice of social research. Cape Town: Oxford University Press

Benoit, C., Shumka, L., Phillips, R., Kennedy, M. C., \& Belle-Isle, L. M. (2015). Issue brief: Sexual violence against women in Canada (p. 33). Status of Women Canada.

Bryman, A. (2016). Social research methods. Oxford university press.

Bue, M. E. (2014). Women's vulnerability, sexual power and prevention of stigma: what do prevention campaigns tell us.

Creswell, J. W., \& Creswell, J. D. (2017). Research design: Qualitative, quantitative, and mixed methods approaches. Sage publications.

Davis, D. R. (2012). A phenomenological study on the leadership development of African American women executives in academia and business.

Eng, S., Szmodis, W., \& Grace, K. (2017). Cambodian remarried women are at risk for domestic violence. Journal of interpersonal violence, 0886260517691520. https://doi.org/10.1177/0886260517691520

Gouws, A. (2017). Feminist intersectionality and the matrix of domination in South Africa. Agenda, 31(1), 19-27. https://doi.org/10.1080/10130950.2017.1338871 
Hegarty, A. (2017). Masculinity, fathers and family literacy: Glimpses behind the 'hard-man'front (Doctoral dissertation, National University of Ireland Maynooth).

Jeffreys, S. (2014). Beauty and misogyny: Harmful cultural practices in the West. Routledge.

Jewkes RK, Dunkle K, Nduna M, Jama PN, Puren A. (2010) Associations between childhood adversity and depression, substance abuse and HIV and HSV2 incident infections in rural South African youth. Child Abuse Negl. 2010 Nov; 34(11),833-41. https://doi.org/10.1016/j.chiabu.2010.05.002

Karakurt G, Silver E. (2013). Emotional abuse in intimate relationships: The role of gender and age. Published in final edited form as: Violence Vict. 28(5):804-21. https://doi.org/10.1891/0886-6708.VV-D-12-00041

Karim, Q. A., \& Baxter, C. (2016). The dual burden of gender-based violence and HIV in adolescent girls and young women in South Africa. SAMJ: South African Medical Journal, 106(12), 1151-1153. https://doi.org/10.7196/SAMJ.2017.v106i12.12126

Lakshmi, P. (2011): UN Women Discussion on Preventing and Ending Violence against Woman: UN Women's publication, New York.

Lobaka, S. T. (2017). Exploring the experiences of young adult women growing up with non-resident fathers in North West Tlokwe Local Municipality (Doctoral dissertation).

Machisa, M., \& Musariri, L. (2013). GBV Indicators Study-Limpopo Province, South Africa.

Maluleke, M. J. (2012). Culture, tradition, custom, law and gender equality. PER: Potchefstroomse Elektroniese Regsblad, 15(1), 02-22.

Muthegheki, S. B., Crispus, K. S., \& Abrahams, N. (2012). An exploratory study of bride price and domestic violence in Bundibugyo District, Uganda. Bundibugyo, Uganda: Centre for Human Rights Advancement. Google Scholar.

Namy, S., Carlson, C., O'Hara, K., Nakuti, J., Bukuluki, P., Lwanyaaga, J., \& Michau, L. (2017). Towards a feminist understanding of intersecting violence against women and children in the family. Social Science \& Medicine, 184, 40-48. https://doi.org/10.1016/j.socscimed.2017.04.042

Parsons, J., Edmeades, J., Kes, A., Petroni, S., Sexton, M., \& Wodon, Q. (2015). Economic impacts of child marriage: a review of the literature. The Review of Faith \& International Affairs, 13(3), 12-22. https://doi.org/10.1080/15570274.2015.1075757
Peterman, A., Palermo, T., \& Bredenkamp, C. (2011). Estimates and determinants of sexual violence against women in the Democratic Republic of Congo. American Journal of Public Health, 101(6), 1060-1067. https://doi.org/10.2105/AJPH.2010.300070

Rafferty, Y. (2013). International dimensions of discrimination and violence against girls: A human rights perspective. Journal of International Women's Studies, 14(1), 1.

Semahegn, A., \& Mengistie, B. (2015). Domestic violence against women and associated factors in Ethiopia; systematic review. Reproductive health, 12(1), 78. https://doi.org/10.1186/s12978-015-0072-1

Senlet, E. T. (2012). Domestic Violence Against Women in Relations to Marital Adjustment and Psychological Well-Being, with the Effects of Attachment, Marital Coping, and Social Support.

Sharma, I. (2015). Violence against women: Where are the solutions?. Indian journal of psychiatry, 57(2), 131. https://doi.org/10.4103/0019-5545.158133

Thobejane, T. D. (2014). Gender expectations within the modern institution of Marriage: A case for South Africa Mediterranean Journal of Social Sciences. Vol 5,2027

UNICEF (2013). A Reference Kit on Violence against Women and Girls in South Asia. ISBN 92-806-3704-5.

United Nations Office on Drugs and Crime (2014). Global Study on Homicide 2013, p. 14

Visser, M., \& Ferrer, S. (2015). Farm Workers' Living and Working Conditions in South Africa: Key Trends, Emergent Issues, and Underlying and Structural Problems. Pretoria: International Labour Organization.

Wechsberg, W. M., Myers, B., Reed, E., Carney, T., Emanuel, A. N., \& Browne, F. A. (2013). Substance use, gender inequity, violence and sexual risk among couples in Cape Town. Culture, health \& sexuality, 15(10), 1221-1236. https://doi.org/10.1080/13691058.2013.815366

Welman, C., Kruger, F., \& Mitchell, B. (2005). Research methodology. Cape Town: Oxford University Press.

World Health Organization. (2012). Female Genital Mutilation, Fact Sheet No. 241. Accessed on 6/20/12 at: http://www.who.int/mediacentre/factsheets/fs241/en/.

World Health Organization. (2012). Understanding and addressing violence against women: femicide.

World Health Organization. (2013). Global and Regional Estimates of Violence against Women: Prevalence and Health Effects of Intimate Partner Violence and Non-Partner Sexual Violence. Report paper, Geneva: Switzerland.

\section{DOl: https://doi.org/10.6000/1929-7092.2019.08.06}

(c) 2019 Tsoaledi Thobejane; Licensee Lifescience Global.

This is an open access article licensed under the terms of the Creative Commons Attribution Non-Commercial License (http://creativecommons.org/licenses/by-nc/3.0/) which permits unrestricted, non-commercial use, distribution and reproduction in any medium, provided the work is properly cited. 